\title{
KAJIAN LINGKUNGAN RENCANA RELOKASI KWPLH BERUANG MADU DI KOTA BALIKPAPAN-PROVINSI KALIMANTAN TIMUR (Environmental Study of Sun Bear KWPLH Relocation Plan in Balikpapan-East Kalimantan)
}

\author{
Sri Ngabekti \\ Jurusan Biologi, Fakultas Matematika dan Ilmu Pengetahuan Alam, Universitas Negeri Semarang, \\ Jalan Raya Sekaran, Gunungpati, Semarang 50229. \\ *Penulis korespondensi. Tel: 024-8508033. Fax: 024-85008005. Email: s_ngabekti@yahoo.com.
}

Diterima: 4 Maret 2015

Disetujui: 24 Agustus 2015

\begin{abstract}
Abstrak
Kawasan Wisata Pendidikan Lingkungan Hidup (KWPLH) beruang madu (Helarctos malayanus) Balikpapan merupakan pusat pendidikan lingkungan yang dianggap sangat profesional, bersih dan dikelola dengan baik. Permasalahannya muncul pada tahun 2013 dengan adanya usulan relokasi beruang madu (dan enklosur) ke Km 10 (Arboretum Wana Wisata Inhutani), karena lokasi yang lama akan dialihfungsikan menjadi bumi perkemahan. Relokasi beruang madu ke habitat baru memerlukan kajian lingkungan yang mendalam untuk menentukan kelayakan lokasi baru sebagai habitat beruang madu. Penelitian ini bertujuan untuk melakukan kajian lingkungan rencana relokasi beruang madu di Balikpapan. Metode penelitian yang digunakan adalah metode survei langsung dengan pengamatan dan pengukuran kondisi lingkungan (fisik/abiotik, biotik). Kuesioner dan pedoman wawancara digunakan untuk mengkaji aspek sosial-budaya di lokasi KWPLH beruang madu (Km 23) dan rencana relokasi di Km 10. Berdasarkan hasil pengukuran, observasi, dan analisis ketiga aspek lingkungan tersebut, dapat disimpulkan bahwa Km 10 dapat digunakan untuk relokasi beruang madu. Namun untuk meminimalisir dampak sosial, direkomendasikan agar beruang madu di Km 23 tidak direlokasi, dan dibuat lagi enklosur beruang madu di Km 10 untuk merawat beruang madu hasil sitaan yang lain.
\end{abstract}

Kata kunci: arboretum, beruang madu, wisata pendidikan, wana wisata.

\begin{abstract}
"Kawasan Wisata Pendidikan Lingkungan Hidup" (KWPLH) of sun bear (Helarctos malayanus) Balikpapan is an environmental education center which is considered to be very professional, clean and well managed. The problem appeared in 2013 with the proposal of sun bear relocation (and enclosure) to Km 10 (Arboretum Wana Wisata Inhutani) because the old location will be converted into a camping ground. Sun bear relocation to a new habitat needs depth environmental study to determine the feasibility of the new location as sun bear habitat. This study aims to conduct an environmental study of sun bear relocation plan in Balikpapan. Research method used in this study is a direct survey method with observation and measurement of environmental conditions ( physical / abiotic, biotic, and socio-cultural) on the location KWPLH sun bear (Km 23) and relocation plan at Km 10, complemented by interviews and document analysis. Based on the results of measurement, observation, and analysis of those three environmental aspects, it can be concluded that the Km 10 can be used to relocate bears. However, to minimize the social impact, it is recommended that sun bears at $\mathrm{Km} 23$ are not relocated, and another sun bear enclosure is made at Km 10 to treat the other of confiscated bears.
\end{abstract}

Keywords: arboretum, educations tour, jungle tour, sun bear.

\section{PENDAHULUAN}

Beruang madu (Helarctos malayanus) merupakan fauna Kalimantan, termasuk salah satu keanekaragaman hayati yang dilindungi. Penelitian beruang madu di alam bebas belum pernah ada, sehingga beruang madu termasuk dalam data deficient dalam Daftar Merah IUCN (IUCN Red List). Penelitian intensif dimulai oleh Fredriksson Tahun 1997-2002 (Fredriksson, 2005 ${ }^{\mathrm{a}}$ ) serta dilanjutkan pada tahun 2005 dan 2010 tentang habitat, perilaku dan ekologi beruang madu di hutan dataran rendah Kalimantan Timur (Fredriksson, 2005 ). Hasil penelitian dengan tanda/bekas, diperoleh informasi bahwa populasi beruang madu hampir tidak ada di wilayah terbakar. Oleh karena itu BKSDA Balikpapan melakukan penyitaan beruang madu yang dipelihara oleh masyarakat sebagai upaya pelestarian.

Mulai tahun 2002 beruang madu dijadikan maskot Balikpapan yang diresmikan berdasarkan SK Walikota Balikpapan No.04 Tahun 2005 Tentang Maskot Kota Balikpapan (Anonim, 2005). 
Sebagai upaya konservasi, tahun 2004-2005 dibangun enklosur beruang madu yang paling bagus di seluruh Asia, dengan boardwalk sepanjang 400 meter. Sk tersebut juga berisi penunjukan Kawasan Agrowisata Km 23 sebagai Kawasan Wisata Pendidikan Lingkungan Hidup (KWPLH) seluas 15 Ha. Dalam SK tersebut Badan Pengelola Hutan Lindung Sungai Wain (BP-HLSW) ditunjuk sebagai pengelola KWPLH. KWPLH bertujuan untuk menyediakan sarana (non-profit) untuk pendidikan lingkungan hidup bagi kepentingan rakyat dan memberi manfaat untuk masyarakat luas (Anonim, 2005).

Pada awal tahun 2006, sebanyak enam ekor beruang madu (4 jantan, 2 betina) yang disita dari warga. Kondisi fisik masing-masing beruang berbeda-beda. Dari keseluruhan, hanya si satu betina yang tidak memiliki cacat fisik, sedangkan beruang yang lain ada yang mengalami buta sebelah mata, bekas luka di dada, tidak lagi memiliki cakar dan taring. Kondisi beruangberuang yang demikian sangat tidak memungkinkan mereka dilepas ke alam liar, karena sudah tidak memiliki organ untuk dapat mempertahankan diri di alam bebas (cakar, taring, mata). Oleh karena itu, melepas beruang tersebut ke alam bebas sama saja dengan membunuh secara tidak langsung (Sitompul dan Anggoro, 2013).

Keenam ekor beruang madu tersebut dipindahkan ke enklosure dengan acara resmi, dan mulai dioperasikan KWPLH. Tahun 2012, KWPLH menerima kunjungan antara 50.000-70.000 orang. Pengunjung terutama anak sekolah, keluarga, perusahaan, grup outbond, ormas, dan lembaga keagamaan. KWPLH menerima kunjungan resmi dari berbagai Kementerian, Kedutaan, Pemerintah Daerah lainnya. Perusahaan besar, Lembaga Internasional yang semua kagum bahwa di Balikpapan dapat ditemukan pusat pendidikan yang dianggap sangat profesional, bersih dan dikelola dengan baik.

Permasalahannya muncul pada tahun 2013 dengan usulan relokasi beruang madu (dan enklosur) ke Km 10 (Arboretum Wana Wisata Inhutani), karena lokasi yang lama akan dialihfungsikan menjadi bumi perkemahan. Relokasi beruang madu ke habitat baru memerlukan kajian lingkungan yang mendalam untuk menentukan kelayakan lokasi baru sebagai habitat beruang madu.

Fredriksson dan Redman (2009) menyatakan habitat beruang madu adalah di hutan hujan tropis. Beruang madu dapat ditemukan di berbagai tipe hutan dataran rendah sampai ke pegunungan maupun hutan gambut. Degradasi habitat dan ketersediaan buah menyebabkan populasinya menurun. Oleh karena itu hamparan hutan yang kecil dengan berbagai tanaman buah sangat penting untuk melindungi beruang madu dari kepunahan. Penelitian tentang habitat satwa juga telah dilakukan Hafsah dkk (2009) tentang karakteristik tanah dan mikroklimat habitat burung maleo dalam upaya pelestarian di Taman Nasional Lore Lindu Sulawesi Tenggara.

Relokasi habitat beruang madu dapat dikaji dari aspek lingkungan fisik atau abiotik, lingkungan biotik, dan lingkungan sosial-budaya. Berdasarkan hasil pengukuran, observasi, dan analisis ketiga aspek lingkungan tersebut, maka dapat ditetapkan apakah relokasi dapat dilakukan. Tulisan ini membahas hasil penelitian kondisi lingkungan KWPLH dibandingkan dengan kondisi lokasi yang baru sehubungan dengan kesesuaiannya sebagai habitat beruang madu.

\section{METODE PENELITIAN}

\section{Waktu dan Lokasi}

Penelitian dilakukan dalam dua tahap. Tahap pertama dilaksanakan pada tanggal 17 Juli 2013 sebagai observasi awal guna melengkapi proposal penelitian yang akan diseminarkan. Tahap kedua dilaksanakan pada tanggal 28-29 Agustus 2013 untuk mengamati dan mengukur kondisi faktor lingkungan di wilayah penelitian.

Penelitian pada dua lokasi yaitu KWPLH Beruang Madu di Km 23 (sebagai habitat lama beruang madu), dan di Arboretum Wana Wisata Inhutani Km 10 Kota Balikpapan (sebagai lokasi yang direncanakan untuk memindahkan beruang madu). KWPLH beruang madu maupun Wana Wisata Inhutani terletak jalan Sukarno-Hatta Km 23 dan Km 10 Karang Joang (poros BalikpapanSamarinda ) Kalimantan Timur. Peta lokasi penelitian dapat dilihat pada Gambar 1.

\section{Prosedur}

Penelitian menggunakan metode survei, yakni melakukan pengamatan dan pengukuran secara langsung kondisi lingkungan di KWPLH dan lokasi baru dimana beruang madu akan direlokasi. Kondisi faktor lingkungan yang diteliti adalah kondisi lingkungan abiotik, biotik, dan sosialbudaya.

Faktor abiotik yang diukur besarannya adalah koordinat lokasi, ketinggian tempat, temperatur dan kelembaban udara, dan intensitas cahaya. Faktor biotik yang diamati adalah kekayaan spesies tumbuhan di dalam enklosur beruang madu yang menjadi sumber daya dan makanan beruang madu, serta hewan-hewan lain yang berinteraksi dengan beruang madu. Untuk memperoleh data kondisi lingkungan sosial - budaya masyarakat tentang 


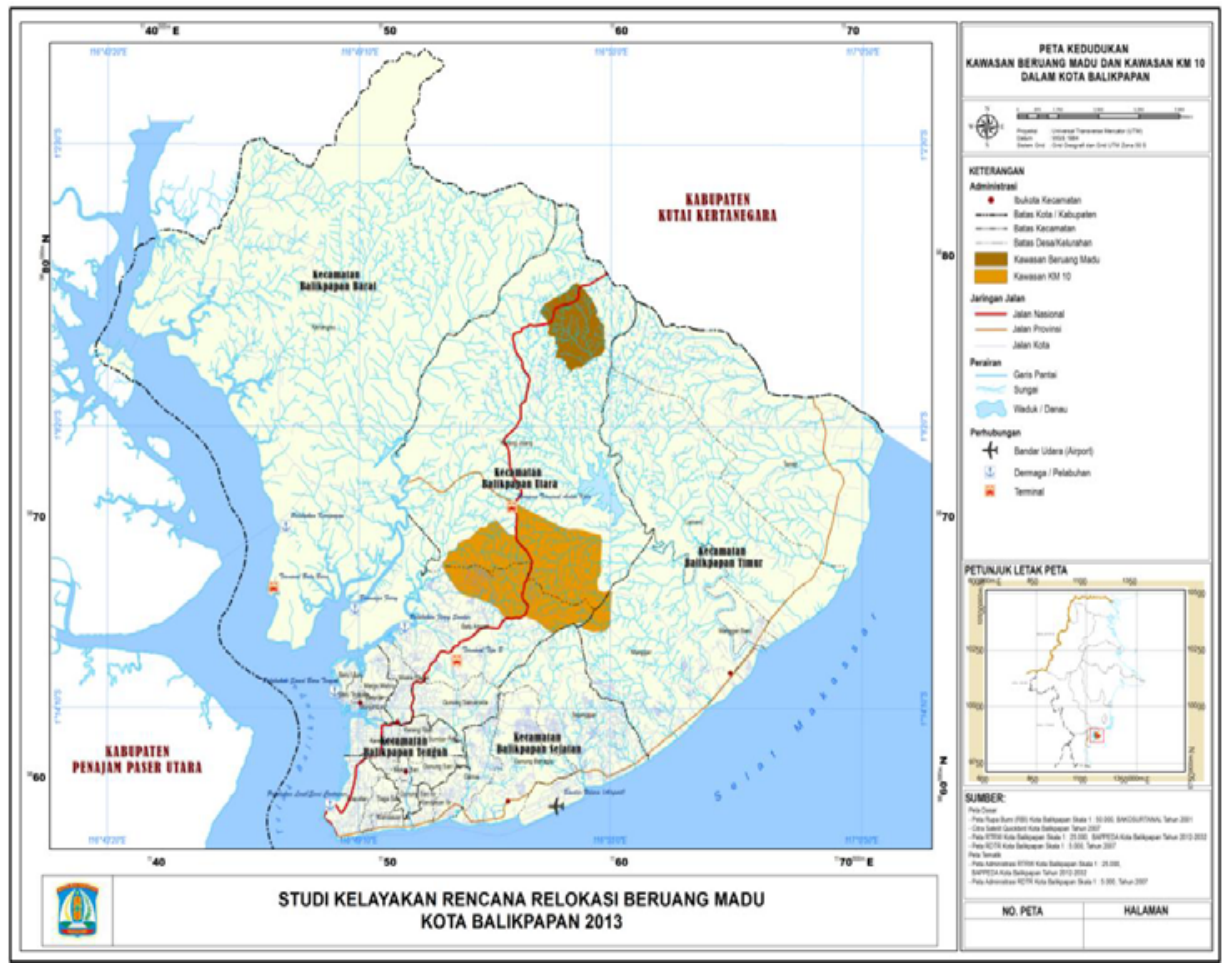

Gambar 1. Peta lokasi KWPLH beruang madu (Km 23) dan Km 10 Balikpapan (Ngabekti dkk, 2013).

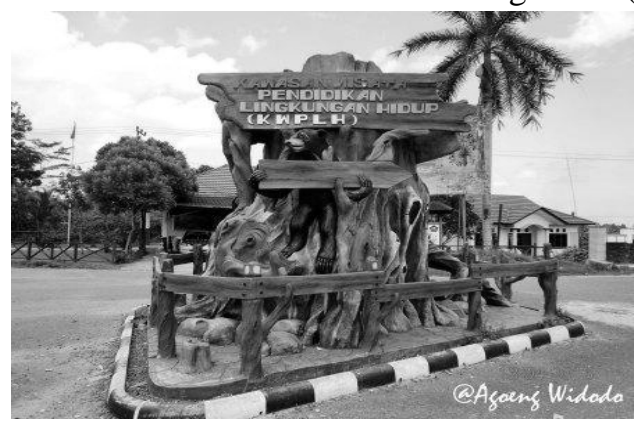

(a)

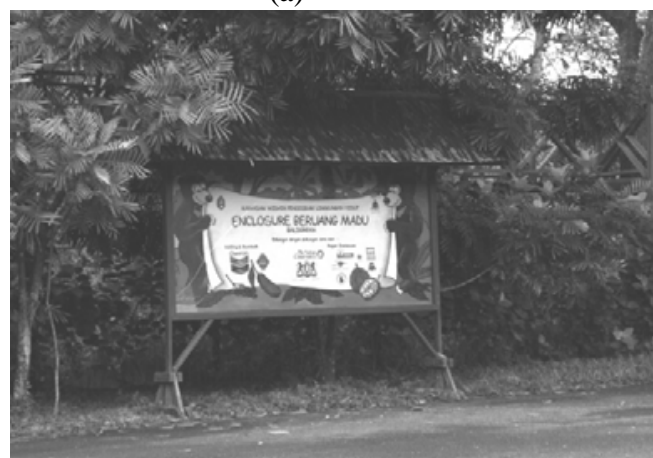

(c)

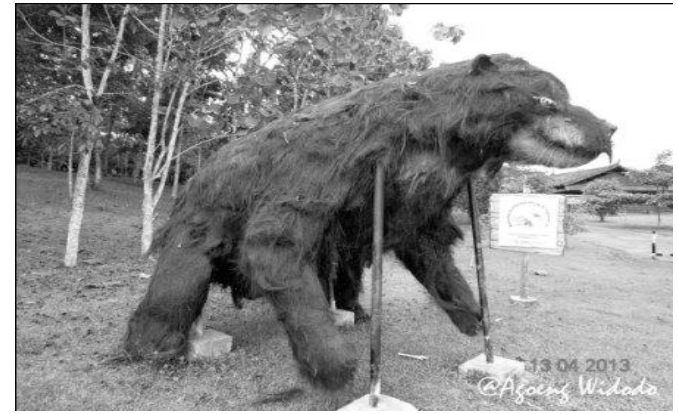

(b)

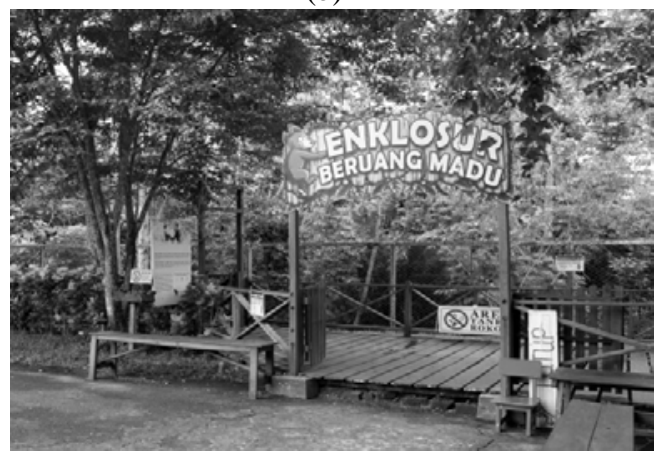

(d)

Gambar 2. Tanda Keberadaan KWPLH Beruang Madu Balikpapan (a) Gapura (b) Patung Beruang Madu (c) dan (d) Enklosur Beruang Madu (Ngabekti dkk, 2013).

keberadaan KWPLH beruang madu dan rencana relokasinya digali melalui kuesioner.

Data hasil pengukuran faktor abiotik dianalisis secara deskriptif kuantitatif. Data kekayaan spesies tanaman di lokasi enklosur beruang madu diperoleh melalui identifikasi, dan data hasil kuesioner aspek sosial masyarakat dianalisis secara deskriptif persentase.

\section{HASIL DAN PEMBAHASAN}

\section{Kondisi lingkungan KWPLH Km 23}

KWPLH enklosur beruang madu pada Km 23 menempati lahan seluas 1,3 hektar. Keberadaan KWPLH ditandai dengan sebuah gapura besar, dengan patung beruang madu di bagian depannya. Sebuah patung beruang madu raksasa dengan bulu- 
bulu dari ijuk serta sebuah papan nama berukuran besar menandakan keberadaan kawasan ini (Gambar 2).

Untuk melengkapi fungsinya sebagai KWPLH, pada bagian luar enklosur juga terdapat Pusat Informasi Beruang di dunia beruang. Tempat ini juga didesain khusus sehingga memudahkan anak-anak dalam memahami jenis-jenis beruang di dunia. Oleh sebab itu tempat ini sangat cocok untuk dijadikan sebagai sarana wisata pendidikan keluarga. Di tempat ini terdapat informasi berbagai macam beruang, habitatnya, makanannya dan halhal lain yang berkaitan dengan aneka beruang di dunia.

Kawasan KWPLH Beruang Madu juga dilengkapi dengan dua buah lamin. Lamin I digunakan untuk berbagai pusat informasi, musholla, toilet, sunbear distro (yang menjual berbagai pernak pernik beruang madu), serta mini theater yang memutar film dokumenter mengenai beruang madu. Lamin II digunakan untuk acara tertentu seperti family gathering dan sebagainya. Kapasitas lamin untuk 250 orang, dan semua acara mendapatkan kegiatan pendidikan lingkungan hidup. Di luar itu masih ada taman bunga dan taman bermain serta tempat piknik keluarga (Ngabekti, 2013).

Dalam leafletnya, KWPLH menggunakan konsep bermain, belajar, dan bertamasya atau play, learn, and relax (Anonim, 2009). Kawasan ini didirikan tahun 2005, menyediakan fasilitas rekreasi ramah lingkungan dan display pendidikan interaktif. KWPLH mempunyai tujuan untuk meningkatkan kesadaran terhadap lingkungan hidup dengan menyediakan fasilitas rekreasi dengan menerapkan prinsip-prinsip ramah lingkungan, menyediakan pendidikan lingkungan hidup, menyadarkan untuk tidak memelihara satwa liar dan mendorong agar bertanggungjawab terhadap hewan domestik yang dipelihara, menyediakan kesempatan rekreasi yang ramah lingkungan, dan meningkatkan apresiasi maskot Kota Balikpapan "Beruang Madu”. Berdasarkan tujuan tersebut, tampak bahwa KWPLH Balikpapan memiliki banyak manfaat, tidak hanya melakukan konservasi beruang madu, tetapi juga mendidik pengunjung untuk ikut serta dalam melestarikan satwa dan lingkungannya.

\section{Kajian Lingkungan Km 10.}

Arboretum Wana Wisata PT Inhutani I Unit Balikpapan pada Km 10 merupakan salah satu objek wisata alternatif selain KWPLH beruang madu di KM 23. Wanawisata ini sudah ada sejak 1972. Koleksi hewan dan tanaman pada awalnya cukup bervariatif. Selain monyet, ada kuda, rusa dan beberapa jenis burung yang diletakkan dalam satu kandang besar. Pada saat ini koleksi tanaman dan hewan di obyek wisata alternatif itu tak selengkap dulu. Hanya tersisa satu ekor monyet, yang dikurung di dalam kandang besi. Hewan yang lain seperti rusa, dan seekor beruang madu sudah dipindah ke lokasi lain.

Wana wisata pada Km 10 memiliki luas 15,2 Ha. Bangunan utamanya adalah pendopo atau gazebo yang menghadap jalan masuk. Gazebo ini sering digunakan pelajar atau mahasiswa untuk menggelar berbagai kegiatan. Selain bangunan tersebut, ada pula lokasi kemah di dalam wana wisata. Dari denah lokasi yang terletak di depan pendopo terlihat ada tiga lokasi kemah yang berdekatan. Selain itu, ada pula lahan yang dikhususkan untuk persemaian tanaman. Di sisi kiri sebelum pendopo ada bangunan berbentuk pos jaga. Tepat di depan pos tersebut terdapat kandang besi besar yang hanya dihuni satu monyet. Di sekitarnya ada bangku bercat warna warni, dan ayunan tempat bersantai. Namun kondisi bangku dan ayunan sudah rusak, sehingga tidak dapat digunakan (Gambar 3).

Pada bagian dalam wana wisata, terlihat beberapa bangku taman yang terkesan tak terurus, karena dibiarkan rusak dengan cat yang terkelupas. Di dalam taman ini terdapat trek-trek (jalur) untuk berolahraga joging serta areal camping di alam terbuka dengan lingkungan yang asri. Taman wisata ini dibuka setiap hari dan dapat ditempuh dengan kendaraan roda dua ataupun roda empat.

Kondisi lingkungan hutan di Arboretum Wana Wisata milik PT Inhutani $1 \mathrm{KM} 10$ cukup bagus. Pohon-pohon rindang sebanyak 52 spesies, menunjukkan suasana alam hutan tropis. Selain itu juga merupakan tempat penelitian tanaman, atau pendidikan yang berkaitan dengan hutan tanaman industri.

Dari ke 52 jenis tanaman tersebut, sebagian besar tanaman di KM 10 merupakan tanaman keras. Hanya ada 9 jenis tanaman buah yang merupakan makanan beruang madu. Selain itu terdapat satu jenis tanaman yakni beringin (Ficus spp.: marga Moraceae) yang juga menghasilkan buah sepanjang waktu, sehingga dapat menjadi sumber makanan ketika buah-buah lain bersifat musiman. Penelitian Wich dan Trisno (2006) menyatakan Moraceae merupakan kelompok buah utama yang dikonsumsi beruang madu selama periode antar musim buah.

\section{Kajian Lingkungan di KWPLH dan Arboretum Wana Wisata Inhutani}

Rencana relokasi beruang madu dari KWPLH (Km 23) ke Wana Wisata Inhutani Km 10 memerlukan kajian lingkungan untuk menentukan 

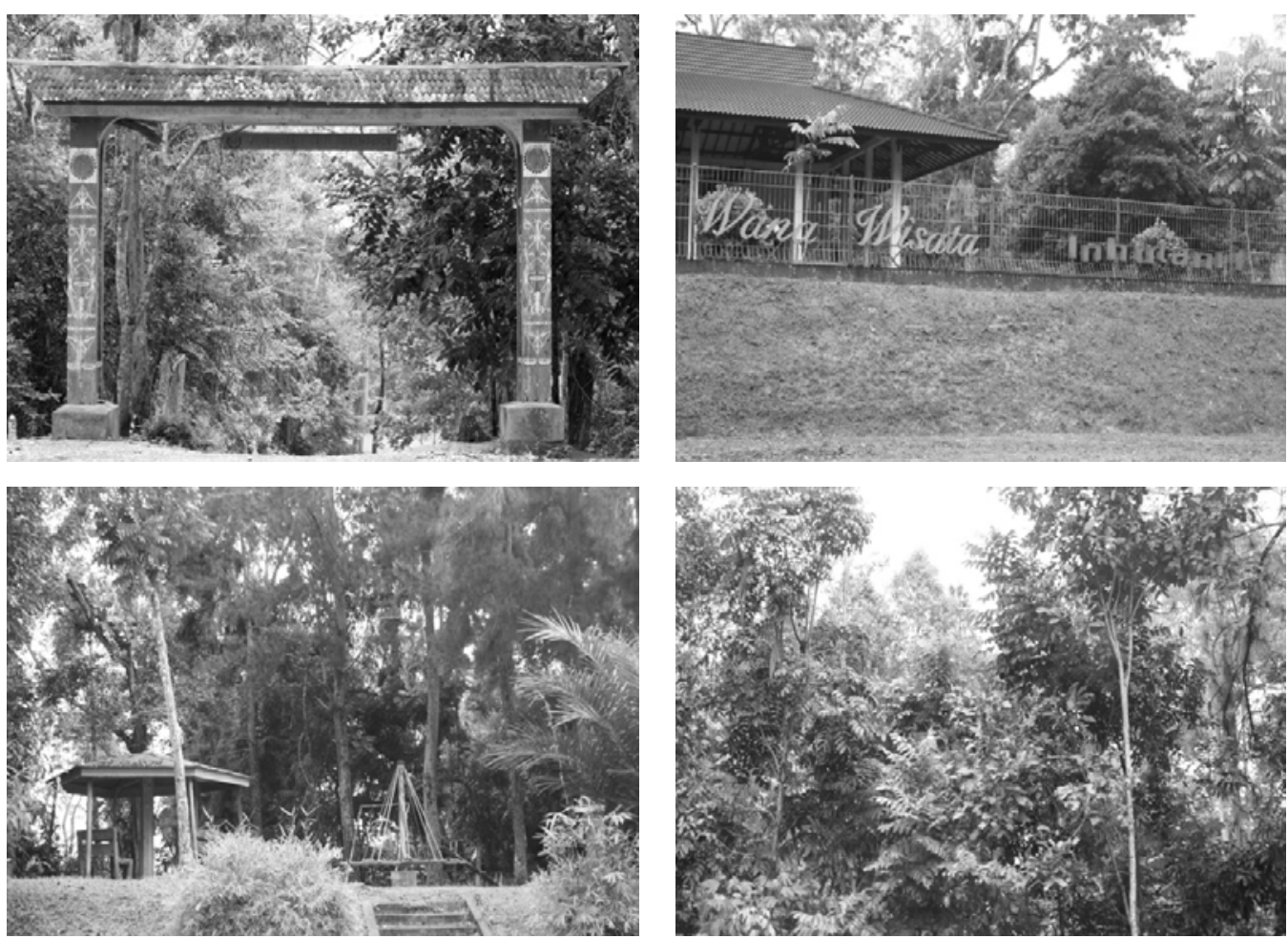

Gambar 3. Kondisi lingkungan arboretum wana wisata Inhutani Balikpapan.

Tabel 1. Hasil penelitian kondisi lingkungan di KWPLH (Km 23) dan Km 10.

\begin{tabular}{|c|c|c|}
\hline Kondisi faktor lingkungan & Km 23 & Km 10 \\
\hline Lingkungan abiotik $^{*}$ & $\begin{array}{l}\text { Luas lahan: } 1,3 \text { ha } \\
\text { Koordinat lokasi: S : } 1^{0} 06 \text { ' } 30.7^{\prime \prime} \text { dan } \\
\text { E : } 116^{0} 54^{\prime} 15.2^{\prime \prime} \text { Ketinggian } 43-68 \\
\text { mdpl, } \\
\text { Suhu udara 24,8-27,6 }{ }^{0} \mathrm{C} \text {, } \\
\text { Kelembaban udara } 85-88 \% .\end{array}$ & $\begin{array}{l}\text { Luas lahan } 15,2 \text { ha, } \\
\text { Koordinat lokasi: S: } 1^{0} 11^{\prime} 27.2^{\prime \prime} \text { dan E : } \\
116^{0} 52^{\prime} 8.46^{\prime \prime} \\
\text { Ketinggian: } 47-63 m d p l \\
\text { Suhu udara: } 26-29 \\
\text { Kelembaban: } 69-88 \%\end{array}$ \\
\hline Lingkungan biotik $^{* *}$ & $\begin{array}{l}\text { Kekayaan spesies tanaman: } 23 \\
\text { spesies, didomonasi oleh tanaman } \\
\text { buah-buahan. }\end{array}$ & $\begin{array}{l}\text { Kekayaan spesies tanaman: } 52 \text { spesies, } \\
\text { didomonasi oleh tanaman keras, }\end{array}$ \\
\hline Lingkungan sosial budaya ${ }^{* * *}$ & 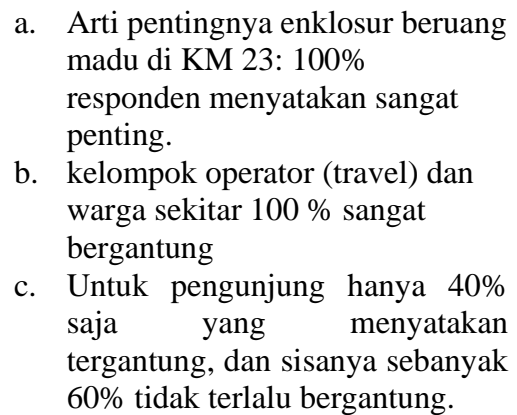 & $\begin{array}{l}\text { a. Informasi terkait adanya relokasi } \\
\text { diketahui oleh } 60 \% \text { persen } \\
\text { responden. } \\
\text { b. Adanya rencana relokasi enklosur } \\
\text { beruang madu ini, sebesar } 100 \% \\
\text { persen menyetujui adanya relokasi. } \\
\text { c. Untuk pengunjung sekitar } 68 \text { persen } \\
\text { responden tidak menyetujui adanya } \\
\text { relokasi dan } \\
\text { d. Untuk operator (travel) } 76 \% \\
\text { menyetujui relokasi }\end{array}$ \\
\hline
\end{tabular}

Keterangan

* Pengukuran dilakukan dalam kondisi pasca hujan.

${ }^{* *}$ Hasil identifikasi ini minimal karena dilakukan di luar pagar kawat berarus listrik.

${ }^{* * *}$ Jumlah responden 30 orang: pengunjung (15 orang), warga sekitar (13 responden), dan sopir angkota (2 responden).

kesesuaian Km 10 sebagai tempat relokasi. Hasil pengukuran dan pengamatan kondisi lingkungan KWPLH Beruang Madu (Km 23) dan Km 10 dapat dilihat pada Tabel 1.

Berdasarkan Tabel 1, kondisi lingkungan abiotik KWPLH beruang madu KM 23 dan Km 10 tidak berbeda secara signifikan, sehingga $\mathrm{Km} 10$ dapat digunakan sebagai habitat baru untuk relokasi beruang madu. Lahan pada $\mathrm{Km} 10$ juga lebih luas. Apabila seluruhnya dimanfaatkan untuk enklosure beruang madu akan sangat memadai, karena akan memperluas daerah jelajah (home range). Salah satu kekurangan lokasi KWPLH km 23 adalah luas enklosur kurang sesuai dengan daerah jelajah 
beruang madu. Hal ini diduga sebagai salah satu penyebab beruang madu belum berhasil untuk berreproduksi.

Kemampuan reproduksi beruang madu merupakan salah satu indikator keberhasilan konservasi ex-situ. Penyebab belum berhasilnya beruang madu berreproduksi di KWPLH Hamsuri (2013) diduga disebabkan dua hal yakni kondisi fisik dan kurang luasnya enklosur. Pertama, beruang madu di kawasan ini berasal dari hasil sitaan, sehingga secara fisik ada bagian tubuh yang cacat. Kedua, kurang luasnya enklosur yang hanya 1,3 hektar untuk wilayah jelajah.

Frederickson $\left(2005^{\mathrm{a}}\right)$ menyatakan beruang madu betina perlu wilayah jelajah minimal 5-10 $\mathrm{km}^{2}$ dalam satu tahun. Beruang jantan memerlukan wilayah jelajah sekitar $15-25 \mathrm{~km}^{2}$. Untuk terjadi proses perkawinan, diperlukan area yang lebih luas. Sementara penelitian Garshelis tahun 2003 yang mengamati gerak-gerik tiga ekor beruang madu selama tahun 1999-2003, wilayah jelajah (periode 12 bulan) adalah $4-5 \mathrm{~km}^{2}$ dengan tumpang tindih antara wilayah jelajah masing-masing individu cukup besar, sehingga berpotensi untuk terjadinya konflik antar individu (Fredriksson, 2012). Wilayah jelajah yang lebih kecil ini diduga berhubungan dengan pola makan yang didominasi oleh serangga, dan tidak adanya panen raya buah di hutan selama penelitian.

Konservasi beruang madu secara ex-situ di KWPLH Balikpapan sampai saat ini dalam rangka mengembalikan kondisi fisiologis dan perilaku beruang madu yang berubah sebagai akibat dipelihara oleh manusia. Penyediaan habitat yang

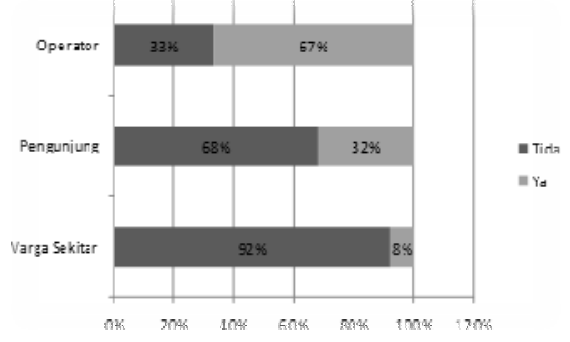

(a)

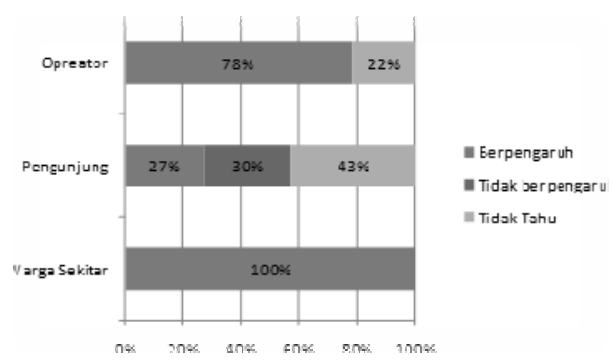

(c) sesuai dengan kondisi alami, merupakan salah satu upaya agar kondisi kehidupan beruang madu lebih baik. Menurut Boer (2013), enklosure beruang madu yang menempati area seluas 1,3 hektar sudah laik. Sangkar luas dilengkapi tempat bermain dan mendapat asupan makanan. Tujuan enklosure memang bukan untuk pengembangbiakan, jadi kemungkinan untuk bertambah jumlahnya sangat kecil. Fredriksson (2012) menyatakan konservasi beruang madu perlu difokuskan pada perlindungan terhadap habitat hutan, managemen yang baik terhadap bidang perlindungan beruang madu, supremasi hukum yang tegas terkait dengan pelanggaran terhadap perlindungan beruang madu, menghentikan perdagangan anggota tubuh beruang, serta mengurangi konflik antara manusia dan beruang madu di wilayah hutan.

Hasil pengukuran kondisi lingkungan pada kedua lokasi (Tabel 1), menunjukkan adanya karakteristik hutan tropis yang menjadi habitat beruang madu. Fredriksson dan Redman (2009) menyatakan habitat beruang madu di hutan hujan tropis, dapat ditemukan pada berbagai tipe hutan, mulai dari hutan dataran rendah sampai ke pegunungan maupun hutan gambut. Minimal harus ada pohon besar karena tempat hidup beruang madu di pepohonan. Beruang madu memiliki kuku yang panjang, digunakan untuk memanjat pohon-pohon yang berbatang lurus pada ketinggian 2-7 meter dari tanah, dan suka mematahkan cabang-cabang pohon atau membuatnya melengkung untuk membuat sarang. Persyaratan adanya pohon besar juga dapat dipenuhi oleh kedua lokasi.

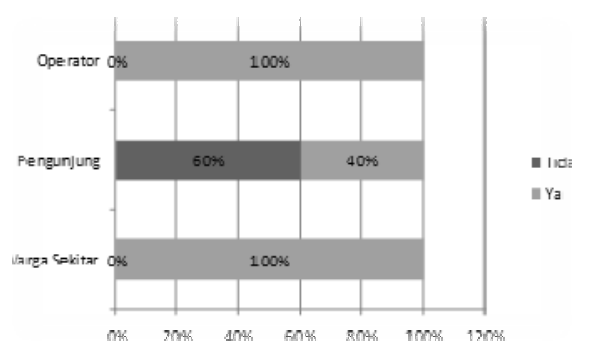

(b)

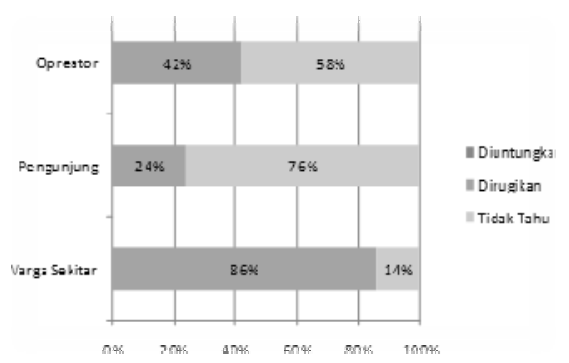

(d)

Gambar 4. Hasil survey sosial budaya (a). tanggapan terkait relokasi enklosure beruang madu, (b). ketergantungan terhadap enklosure beruang madu, (c). perasaan pengaruh keberadaan enklosure beruang madu dan (d). perasaan diuntungkan atau dirugikan jika relokasi enklosure beruang madu. 


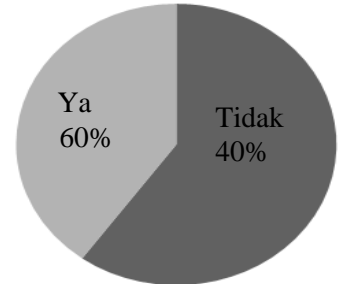

Gambar 5. Grafik informasi terkait relokasi enclosure beruang madu KM 23.

Persyaratan lain yang harus diperhatikan adalah tanaman buah-buahan untuk mencukupi kebutuhan makanan beruang madu. Kondisi lingkungan biotik di $\mathrm{Km} \mathrm{23,} \mathrm{dalam} \mathrm{enklosur}$ beruang madu didominasi oleh buah-buahan, sesuai dengan sumber daya yang dibutuhkan oleh beruang madu sebagai bahan makanan. Buah-buahan ini sebagian sengaja ditanam, sebagian yang lain tumbuh dari biji buah-buahan dai makanan yang diberikan oleh pengelola. Menurut Fredriksson dan Redman (2009), beruang madu adalah penyebar biji yang paling efisien di hutan Kalimantan, karena biji pada buah yang dimakan ditelan tanpa mengunyahnya. Beruang madu juga beraktivitas cukup jauh dan menyebarkan biji pada wilayah yang luas.

Penelitian Wich dan Trisno (2006) di hutan Kalimantan pasca kebakaran akibat terjadinya $E l$ Nino Southern Oscillation (ENSO) antara tahun 1997-2006, menemukan bahwa beruang madu hampir tidak mengkonsumsi selain buah selama sekitar dua bulan tersedianya buah. Selama penelitian tersebut, beruang madu diketahui mengkonsumsi setidaknya 115 spesies buah, dengan lebih dari 50\% buah yang dimakan berasal dari marga Moraceae, Burseraceae dan Mirtaceae. Oleh karena itu, apabila Km 10 akan dijadikan lokasi untuk memindahkan beruang madu, maka harus diperbanyak tanaman buah-buahan dan pohon beringin (marga Moraceae).

Hasil survai kondisi lingkungan sosial-budaya: tanggapan, ketergantungan, perasaan terpengaruh, dan kemungkinan untung rugi terkait relokasi enklosur beruang madu dapat dilihat pada Gambar 4. Informasi tentang rencana relokasi beruang madu telah diketahui oleh $60 \%$ responden. Sisanya $40 \%$ menyatakan tidak mengetahui (Gambar 5).

\section{KESIMPULAN}

Berdasarkan hasil kajian kondisi lingkungan dan uraian kajian pustaka, dapat disimpulkan bahwa beruang madu di KWPLH Km 23 dapat direlokasi ke Arboretum Wana Wisata Inhutani Km
10, dengan beberapa persyaratan: peningkatan terhadap fasilitas, daya jangkau angkutan umum relatif mudah, perbaikan sistem dan keamanan, serta keberadaan enklosure yang memadai.

Relokasi beruang madu di KWPLH Km 23 ke Km 10 akan terjadi beberapa kendala yang serius seperti masalah sosial (terjadi konflik sosial saat pemindahan) yaitu banyak warga sekitar akan kehilangan lahan pekerjaannya. Transportasi dan daya dukung lahan untuk enklosur beruang madu tersebut mendukung, tetapi akan timbul biaya investasi yang besar untuk relokasi.

\section{UCAPAN TERIMAKASIH}

Ucapan terima kasih disampaikan kepada Pemerintah Kota Balikpapan melalui PT Karsa Haryamulya Semarang yang telah membantu dalam dana penelitian.

\section{DAFTAR PUSTAKA}

Anonim, 2005. Surat Keputusan Walikota Balikpapan No. 188.45-72 tentang Penetapan Beruang Madu sebagai Maskot Kota Balikpapan. Balikpapan.

Anonim, 2009. Kawasan Wisata Pendidikan Lingkungan Hidup. Bermain, Belajar, Bertamasya, website : www.beruangmadu.org.

Boer, C., 2013. Peneliti Jamin Pemindahan Enklosure Tidak Masalah. Pos Metro Balikpapan. 4 Maret 2013.

Fredriksson, G. 2005 ${ }^{\mathrm{a}}$. Human-Sun Bears Conflicts in East Kalimantan. Ursus, 16:130-137.

Fredriksson, G. 2005 . Predation on Sun Bears by Reticulated Python in East Kalimantan, Indonesian Borneo. The Raffles Bulletin of Zoology, 53(1):165-168

Fredriksson, G dan Redman, A., 2009. A Little Book about A Little Bear. KWPLH. Balikpapan.

Fredriksson, G. 2012. Effect of El Nino and LargeScale Forest Fires on the Ecology and Concervation of Malayan Sun Bears (Helarctos malayanus) in East Kalimantan, Indonesian Borneo. Academisch Proefschrift. Geboren te Amsterdam, Amsterdam.

Hafsah, T., Yuwanto, Kustono, dan Djuwantoko, 2009. Karakteristik Tanah dan Mikroklimat Habitat Burung Maleo (Macrochepalon maleo) di Taman Nasional Lore Lindu Sulawesi Tenggara. Jurnal Manusia dan Lingkungan,16(2):75-80.

Hamsuri, 2013. Beruang Madu belum Bisa Reproduksi (Komunikasi Pribadi) 
Ngabekti, S., Setiono, W, dan Ana, Y, 2013. Studi Kelayakan Relokasi Beruang Madu Kota Balikpapan. PT Karsa Haryamulya, Balikpapan:

Ngabekti, 2013. Konservasi Beruang Madu di KWPLH Balikpapan. Biosaintifika: Journal of Biology \& Biology Education, 5(2):90-96
Sitompul, P.G., dan Anggoro, D., 2013. Beruang Madu Sang Maskot Balikpapan. BKSDA Kalimantan Timur. Balikpapan.

Wich S.A. dan Trisno, 2006. Frugivory in Sun Bears (Helarctos malayanus) is linked to $\mathrm{El}$ Nino-related Fluctuation in Fruiting phenology. Biological Journal of the Linnean Society, 89(3):489-508. 